\title{
KEPEMIMPINAN KEPALA SEKOLAH PEREMPUAN PADA SEKOLAH EFEKTIF
}

\author{
Besse Marhawati \\ bessemarhawati@ung.ac.id \\ Universitas Negeri Gorontalo Jl. Jenderal Sudirman 6 Gorontalo 96128
}

\begin{abstract}
Abstrak: This study aimed to describe the leadership of female principal in effective schools of MIT Al-Islah Kota Gorontalo. The approach methodology that used in this study was a qualitative with case study design. Data analysis was performed by the steps: data reduction, data presentation, drawing conclusions or verification of data records that obtained from observations and interviews. The results of the study as follows: (1) strategy of the principal women in achieving effectiveness in MIT Al-Islah Kota Gorontalo include: (a) optimal learning (b) empowering the potency of the students, and (c) establishing the cooperation with various partners to support student's achievement; (2) supporting factors in improving student achievement at MIT Al-Islah Kota Gorontalo that include: (a) inputing data of students who excel and selected that prioritized for RA graduates of Al-Islah, this inputing not limited insiders but also for for the public by advertising, where ranking system was taken based on the results of testing that consists of psychological tests (independence) was used, academic tests (math and reading), testing skills (memorizing short chapters); and (b) obtaining support from the school components.
\end{abstract}

keyword: female school leadership, effective schools

\begin{abstract}
Abstrak: Penelitian ini bertujuan untuk mendeskripsikan kepemimpinan kepala sekolah perempuan pada sekolah efektif di MIT Al-Ishlah Kota Gorontalo. Pendekatan yang digunakan dalam penelitian ini adalah pendekatan kualitatif dengan rancangan studi kasus. Analisis data dilakukan dengan langkah-langkah yaitu: reduksi data, penyajian data, penarikan kesimpulan atau verifikasi yang diperoleh melalui catatan hasil observasi dan hasil wawancara. Hasil penelitian sebagai berikut: (1) strategi kepala sekolah perempuan dalam mencapai sekolah efektif di MIT Al-Ishlah Kota Gorontalo yang meliputi: (a) optimalisasi pembelajaran, (b) memberdayakan potensi siswa, dan (c) menjalin kerja sama dengan berbagai pihak untuk mendukung prestasi siswa; (2) faktor- faktor pendukung dalam meningkatkan prestasi siswa di MIT Al-Ishlah Kota Gorontalo meliputi: (a) input siswa yang unggul dan terseleksi, diprioritaskan bagi lulusan RA Al-Ishlah, tetapi juga terbuka untuk umum melalui iklan dengan sistem rangking yang didasarkan pada hasil testing yang terdiri tes psikologi (kemandirian), tes akademik (berhitung dan membaca), tes keterampilan (hafalan surah pendek); dan (b) memperoleh dukungan dari komponen sekolah.
\end{abstract}

Kata kunci: kepemimpinan kepala sekolah perempuan, sekolah efektif

Sekolah sebagai organisasi untuk mencapai tujuannya tidak lepas dari kepemimpinan kepala sekolahnya dalam mempengaruhi dan menggerakkan orang-orang yang terkait dalam penyelenggaraan pembelajaran di sekolah. Sebagaimana yang dikatakan oleh Kartono (2002) bahwa keberhasilan organisasi dalam mencapai tujuan yang ingin diraih bergantung kepada kepemimpinannya, yaitu apakah pemimpin tersebut mampu menggerakkan semua sumber daya manusia, sarana, dana, dan waktu secara efektif dan efisien serta terpadu dalam proses manajemen.

Kepemimpinan kepala sekolah adalah salah satu faktor yang dapat mendorong sekolah untuk dapat mewujudkan visi, misi, tujuan, dan sasaran sekolahnya melalui program-program yang dilaksanakan secara terencana dan bertahap. Oleh karena itu, kepala sekolah dituntut mempunyai kemampuan manajemen dan kepemimpinan 
yang memadai agar mampu meningkatkan mutu sekolah. Triwiyanto (2013:125) menyatakan bahwa disamping diperlukan kemampuan manajemen dan kepemimpinan, komponen pengendalian manajemen Sumber Daya Manusia (SDM) pendidikan atau sering disebut dengan manajemen pendidik dan tenaga kependidikan sangat dibutuhkan. Komponen ini menjadi tumpuan bagi proses pembelajaran yang berkualitas.

Perempuan yang menjadi seorang pemimpin formal termasuk kepala sekolah atau sebagai perempuan karir dalam hal ini banyak menghadapi masalah, terutama berhubungan dengan posisi yang bersangkutan dalam karir dan rumah tangga. Perempuan sebagai pemimpin tidak jarang menghadapi banyak hambatan yang berasal dari sikap budaya masyarakat yang keberatan, mengingat bahwa laki-laki berfungsi sebagai pelindung dan kepala keluarga. Begitupula hambatan fisik wanita yang dianggap tidak mampu melaksanakan tugas-tugas berat.

Tan (1991:16), menguraikan beberapa hambatan yang muncul dari kepemimpinan perempuan sebagai berikut: Pertama, hambatan fisik. Perempuan, katanya dibebani tugas-tugas "kontrak" untuk mengandung, melahirkan, dan menyusui. Keharusan ini mengurangi keleluasaan mereka untuk aktif terus-menerus dalam berbagai bidang kehidupan. Bayangkan jika perempuan harus melahirkan sampai selusin anak, pastilah usia produktifnya habis dipakai untuk tugas-tugas reproduktif yang mulia itu. Kedua, hambatan teologis bahwa untuk waktu yang lama perempuan dipandang sebagai makhluk yang dicipta untuk lelaki, temasuk mendampingi mereka, menghiburnya, dan mengurus keperluannya. Perempuan, menurut cerita teologis diciptakan dari tulang rusuk laki-laki. Cerita ini telah jauh merasuk dalam benak banyak orang dan secara psikologis menjadi salah satu faktor penghambat perempuan untuk mengambil peran yang berarti. Ketiga, hambatan sosial budaya terutama dalam bentuk stereotipikal. Pandangan ini melihat perempuan sebagai makhluk pasif, lemah, perasa, tergantung, dan menerima keadaan. Sebaliknya, lelaki dinilai sebagai makhluk yang aktif, kuat, cerdas, mandiri, dan sebagainya. Pandangan ini menempatkan laki-laki secara sosio-kultural lebih tinggi derajatnya dibanding perempuan. Keempat, hambatan sikap pandang yang antara lain dimunculkan oleh pandangan dikotomis antara tugas perempuan dan laki-laki. perempuan dinilai sebagai makhluk rumah, sedangkan laki-laki dilihat sebagai makhluk luar rumah. Pandangan dikotomis seperti ini boleh jadi telah membuat perempuan merasa risih keluar rumah, dan pandangan bahwa tugas-tugas kerumahtanggaan tidak layak digeluti laki-laki. Kelima, hambatan historis. Kurangnya nama perempuan dalam sejarah di masa lalu bisa dipakai membenarkan ketidakmampuan perempuan untuk berkiprah seperti halnya laki-laki.

Begitu pula studi yang dilakukan oleh Meskhin (dalam Sergiovanni, 1987) menyimpulkan bahwa perempuan cenderung menggunakan perilaku yang bersifat demokratis dalam performasinya sebagai kepala sekolah dan pelaksanaan tugas administratifnya sangat efektif. Demikian juga dalam penelitian Gilligan (dalam Rimmer \& Davis, 1986) menemukan bahwa dalam realitas sosial perempuan selalu melakukan hubungan dengan lebih hati-hati dan kooperatif.

Penelitian lainnya adalah penelitian yang menyoroti tinjauan ulang dari penelitian Meskhin yaitu penelitian yang dilakukan oleh Gross dan Task (dalam Sergiovanni, 1987). Penelitian Gross dan Task menggunakan beberapa indikator dalam penelitiannya, yaitu penampilan perempuan sebagai kepala sekolah, moral guru, dan prestasi anak didik. Penelitian ini menyimpulkan bahwa penampilan perempuan sebagai kepala sekolah tampak lebih baik dibandingkan dengan laki-laki, moral guru lebih ditekankan pada penguasaan keterampilan teknik dan tanggung jawab mereka terhadap organisasi 
sekolah, dan kepala sekolah banyak menggunakan kontrol supervisi.

$\begin{array}{rcc}\text { Beberapa } & \text { penelitian } & \text { tersebut } \\ \text { menunjukkan bahwa kepala } & \text { sekolah }\end{array}$
perempuan lebih memiliki kemampuan dalam menghasilkan kepemimpinan yang efektif pada pencapaian tujuan pendidikan di sekolah dan mendukung pelaksanaan sekolah efektif.

Strategi yang dilakukan kepala sekolah dalam mencapai sekolah efektif antara lain: (1) optimalisasi proses pembelajaran, (2) memberdayakan potensi siswa, dan (3) menjalin kerja sama dengan berbagai pihak untuk mendukung prestasi siswa. Sedangkan faktor-faktor pendukung dalam meningkatkan prestasi sekolah adalah: (1) input siswa yang unggul dan terseleksi, (2) memperoleh dukungan dari komponen sekolah, (3) jalinan kerjasama dan kemitraan dengan orang tua, masyarakat, pemerintah, pihak swasta, dan lembaga pendidikan internasional (Fauzuddin, 2011).

Madrasah Ibtidaiyah Terpadu Al-Ishlah (MIT) A-Ishlah Kota Gorontalo merupakan salah satu sekolah yang dipimpin oleh kepala sekolah perempuan yang dipandang sukses dalam memimpin sekolahnya untuk mencapai sekolah efektif terutama sebagai tempat belajar paling baik dalam menyediakan layanan pembelajaran bermutu bagi siswa.

\section{METODE}

Penelitian ini bertujuan untuk mendeskripsikan tentang kepemimpinan kepala sekolah perempuan pada sekolah efektif di MIT Al-Ishlah Kota Gorontalo. Rancangan penelitian ini adalah studi kasus. Pengumpulan data dilakukan oleh peneliti sendiri sebagai instrumen utama yang dilakukan pada latar alamiah. Teknik pengumpulan dalam penelitian ini adalah observasi, wawancara, dan dokumentasi. Data yang dikumpulkana terkait dengan Strategi yang dilakukan kepala sekolah perempuan dalam mencapai sekolah efektif, dan Faktor-faktor pendukung dalam meningkatkan prestasi sekolah di MIT AlIshlah Kota Gorontalo. Sumber data dalam penelitian ini adalah kepala madrasah, wakil kepala madrasah, guru-guru, dan orang tua siswa. Data yang dikumpulkan dianalisis secara deskriptif melalui alur: reduksi data, penyajian data, dan penarikan kesimpulan.

\section{HASIL}

Strategi yang dilakukan kepala sekolah perempuan dalam mencapai sekolah efektif di MIT Al-Ishlah Kota Gorontalo yaitu: (1) optimalisasi proses pembelajaran adalah melalui pembelajaran di kelas yang dilaksanakan pada hari senin sampai dengan hari Jumat. Apabila dalam pembelajaran, siswa ada yang mengalami kesulitan atau dianggap masih rendah dalam mata pelajaran tertentu, maka disarankan untuk mengikuti bimbingan khusus yang dinamakan super kelas. Super kelas dilakasanakan berdasarkan atas kesepakatan dengan orang tua di luar jam pelajaran. Sedangkan untuk hari Sabtu dikhususkan pada program pengembangan diri misalnya membaca di perpustakaan atau menonton video tentang tata cara sholat, tata cara berwudhu, tata cara berpakaian, dan hubungan sosial. Bagi siswa yang memiliki hobi di bidang seni seperti menari, menyanyi, puisi, peragaan busana disiapkan panggung khusus; (2) memberdayakan potensi siswa, yaitu melalui pemberdayaan potensi siswa pada bidang pendidikan siswa dengan mengikuti olimpiade matematika, dan cerdas cermat. Pada bidang seni siswa mengikuti lomba menari, vokalia, peragaan busana. Pada bidang agama, siswa mengikuti lomba tahfis atau hafalan surah, puasa senin-kamis, sholat Dhuha, dan sholat Dhuhur untuk siswa kelas tinggi. Pada bidang sosial siswa diikutkan kerja bakti, dan kunjungan ke Panti Asuhan. Untuk memaksimalkan pemberdayaan potensi siswa dilengkapi dengan buku penghubung informasi sebagai sarana guru dan orang tua dalam memantau aktifitas siswa baik di sekolah maupun di rumah; (3) menjalin kerjasama dengan berbagai pihak untuk mendukung prestasi siswa yaitu (a) menjalin kerjasama dengan orang tua siswa dalam pengadaan media (alat pembelajaran), kegiatan ekstra kurikuler, memberi informasi akses yang 
terkait dengan kegiatan sekolah, (b) menjalin kerjasama dengan masyarakat di sekitar sekolah dalam menjamin keamanan dan kenyamanan sekolah, serta mendukung kegiatan sekolah, (c) menjalin kerjasama dengan pemerintah melalui pemberian dana BOS dan Beasiswa Miskin, (d) menjalin kerjasama dengan Dinas terkait seperti Balai POM melalui penyuluhan makanan dan obat-obatan, Dinas Kesehatan (Puskemas) melalui penyuluhan kesehatan badan dan gigi, dan pengobatan gratis, dan (e) menjalin kerjasama dengan pihak Bank Muamalat dan Pegadaian sebagai donator dalam kegiatan Milad dan buka puasa bersama pada bulan Ramadhan.

Faktor-Faktor Pendukung dalam Meningkatkan Prestasi Sekolah di MIT Al- Ishlah Kota Gorontalo yaitu: (1) input siswa yang unggul dan terseleksi, bahwa input siswa diprioritaskan pada lulusan RA Al-Ishlah, tetapi juga terbuka untuk umum melalui iklan dengan sistem rangking yang didasarkan pada hasil testing yang terdiri tes psikologi (kemandirian), tes akademik (berhitung dan membaca), tes keterampilan (hafalan surah pendek); (2) memperoleh dukungan dari komponen sekolah, bahwa dukungan dari komponen sekolah terutama guru dalam mendukung program sekolah nampak dari komitmen guru dalam melaksanakan tugas yang telah ditetapkan, mengikuti rapat setiap hari pukul 14.00 untuk pemantapan pembelajaran yang dilaksanakan, dan guru-guru juga aktif mengikuti pelatihan pembelajaran (excellent service) melalui Jaringan Sekolah Islam Terpadu setiap tahun ajaran baru.

\section{PEMBAHASAN}

Strategi yang dilakukan kepala sekolah perempuan dalam mencapai sekolah efektif di MIT Al-Ishlah Kota Gorontalo meliputi: pertama, optimalisasi pembelajaran yang dilakukan melalui pembelajaran di kelas dan di luar kelas untuk memberikan pengalaman belajar agar terjadi perubahan pada siswa. Sebagaimana dikemukakan Driscoll, 2000; Hill, 2002, Schunk, 2004 (dalam Slavin, 2011:177) bahwa pembelajaran sebagai perubahan dalam diri seseorang yang disebabkan oleh pengalaman. Jadi pembelajaran di sekolah hendaknya dapat memberikan pengalaman belajar yang baik sehingga mampu meningkatkan potensi prestasi pada siswa. Optimalisasi pembelajaran siswa di MIT Al-Islah Kota Gorontalo yaitu pembelajaran di kelas dilaksanakan pada hari senin sampai hari Jumat. Apabila dalam pembelajaran, siswa ada yang mengalami kesulitan atau dianggap masih rendah dalam mata pelajaran tertentu, maka disarankan untuk mengikuti super kelas berdasarkan atas kesepakatan dengan orang tua di luar jam pelajaran. Sedangkan untuk hari Sabtu dikhususkan pada program pengembangan diri misalnya membaca di perpustakaan atau menonton video tentang tata cara sholat, tata cara berwudhu, tata cara berpakaian, dan hubungan sosial. Bagi siswa yang memiliki hobi di bidang seni seperti menari, menyanyi, puisi, peragaan busana disiapkan panggung khusus.

Kedua, memberdayakan potensi siswa. Pembelajaran di sekolah hendaknya menyadari hal tersebut sehingga pembelajaran dapat memberikan pengalaman belajar yang baik dan mampu meningkatkan potensi peserta didik. Sebagaimana pendapat Slavin, (2011) bahwa jumlah kecerdasan yang tepat tidak penting bagi pendidik. Yang penting ialah gagasan bahwa kinerja yang baik atau buruk dalam satu bidang sama sekali tidak menjamin kinerja serupa dalam bidang lain. Guru harus menghindari berpikir tentang siswa sebagai orang cerdas atau tidak cerdas, karena ada banyak cara untuk menjadi cerdas. Apabila sekolah menginginkan semua siswa menjadi cerdas, mereka harus menggunakan rentang kegiatan yang lebih luas dan memberi imbalan bagi rentang kinerja yang lebih luas daripada yang mereka lakukan pada masa lalu. Untuk memberdayakan potensi siswa di MIT Al-Islah Kota Gorontalo, di bidang pendidikan siswa mengikuti olimpiade matematika, dan cerdas cermat. Bidang seni siswa mengikuti lomba menari, vokalia, peragaan busana. Pada bidang agama, siswa mengikuti lomba tahfis atau hafalan surah, puasa senin-kamis, sholat Dhuha, dan sholat Dhuhur untuk siswa kelas tinggi. Bidang sosial siswa diikutkan kerja bakti, dan kunjungan ke Panti Asuhan. Sedangkan untuk memaksimalkan pemberdayaan potensi siswa dilengkapi dengan buku penghubung informasi sebagai sarana guru dan orang tua dalam memantau aktivitas siswa baik di sekolah maupun di rumah.

Ketiga, menjalin kerjasama dengan berbagai pihak untuk mendukung prestasi siswa. Sekolah 
dalam proses pertumbuhan dan perkembangannya tidak lepas dari dukungan berbagai pihak dalam hal ini pemerintah, masyarakat, dan orang tua siswa. Oleh karena itu pihak sekolah hendaknya mampu melakukan kerjasama dengan baik khususnya dalam mendukung prestasi siwa. Dalam menjalin kerjasama dengan berbagai pihak untuk mendukung prestasi siswa di MIT Al-Ishlah Kota Gorontalo dilakukan melalui kerjasama dengan orang tua dalam pengadaan media (alat pembelajaran), kegiatan ekstra kurikuler, memberi informasi akses yang terkait dengan kegiatan sekolah, kerjasama dengan masyarakat dalam menjamin keamanan dan kenyamanan sekolah, serta mendukung kegiatan sekolah, kerjasama dengan pemerintah melalui BOS, Beasiswa Miskin dan kerjasama dengan dinas terkait seperti Balai POM, Dinas Kesehatan (Puskemas), dan kerjasama juga dilakukan dengan pihak Bank dan Pegadaian sebagai sponsor.

Hal tersebut menggambarkan bahwa MIT Al-Ishlah Kota Gorontalo mampu menjalin kerjasama yang baik dengan berbagai pihak dalam mendukung prestasi sekolah. Kedepan, bentuk kerjasama tersebut perlu dipelihara dan ditingkatkan demi kemajuan sekolah.

Faktor-faktor pendukung dalam meningkatkan prestasi sekolah di MIT Al- Ishlah Kota Gorontalo yaitu: pertama, input siswa yang unggul danterseleksi. Setiap sekolahmemilikicara sendiri untuk menentukan calon siswa yang akan diterimanya. Prihatin (dalam Suking, 2013:27) mengemukakan bahwa agar seseorang diterima sebagai siswa suatu sekolah haruslah memenuhi persyaratan-persyaratan sebagaimana yang telah ditentukan. Penentuan mengenai jumlah siswa, tentu juga didasarkan atas kenyataan-kenyataan yang ada di sekolah yang meliputi: daya tampung kelas baru, kriteria mengenai siswa, kriteria siswa yang dapat diterima, anggaran yang tersedia, sarana dan prasarana yang ada, tenaga kependidikan tersedia, jumlah siswa yang tinggal di kelas satu, dan sebagainya. Input siswa di MIT Al-Ishlah Kota Gorontalo, diprioritaskan bagi lulusan RA Al-Ishlah, tetapi juga terbuka untuk umum melalui iklan dengan sistem rangking yang didasarkan pada hasil testing yang terdiri tes psikologi (kemandirian), tes akademik (berhitung dan membaca), tes keterampilan (hafalan surah pendek). MIT Al-Ishlah Kota Gorontalo memiliki input siswa melalui seleksi yang didasarkan pada kriteria-kriteria yang telah ditetapkan.

Kedua, memperoleh dukungan dari komponen sekolah. Kesuksesan sekolah dalam mencapai tujuannya tentu membutuhkan dukungan dari komponen sekolah terutama guru. Guru merupakan faktor penting pembelajaran. Oleh karena itu pihak sekolah dalam hal ini kepala sekolah senantiasa berupaya meningkatkan kemampuan gurunya. Dukungan guru di MIT Al-Ishlah Kota Gorontalo, nampak pada komitmen guru dalam melaksanakan tugas yang telah ditetapkan, mengikuti rapat setiap hari untuk pemantapan pembelajaran yang dilaksanakan. Guru juga aktif mengikuti pelatihan pembelajaran (excellent service) setiap tahun ajaran baru melalui Jaringan Sekolah Islam Terpadu demi meningkatkan kemampuan profesionalnya. Guru-guru di MIT Al-Ishlah Kota Gorontalo memiliki komitmen yang tinggi dalam pelaksanaan program sekolah.

\section{KESIMPULAN DAN SARAN}

\section{Kesimpulan}

Strategi yang dilakukan kepala sekolah perempuan dalam mencapai sekolah efektif di MIT Al-Ishlah Kota Gorontalo yang meliputi: (1) optimalisasi pembelajaran dilakukan dengan pembelajaran di kelas pada hari senin sampai hari jumat. Bagi siswa yang mengalami kesulitan atau dianggap masih rendah dalam mata pelajaran tertentu, disarankan mengikuti super kelas yang dilaksanakan diluar jam pelajaran. Pada hari Sabtu dikhususkan pada program pengembangan diri misalnya membaca diperpustakaan atau menonton video tentang tata cara sholat, tata cara berwudhu, tata cara berpakaian, dan hubungan sosial. Bagi siswa yang memiliki hobi di bidang seni seperti menari, menyanyi, puisi, peragaan busana disiapkan panggung khusus; (2) memberdayakan potensi siswa, pada berbagai bidang yaitu bidang pendidikan, siswa mengikuti olimpiade matematika, dan cerdas cermat. Bidang seni, siswa mengikuti lomba tari, vokalia, peragaan busana. Bidang agama, siswa mengikuti lomba tahfis atau hafalan surah, puasa seninkamis, sholat Dhuha, dan sholat Dhuhur untuk siswa kelas tinggi. Bidang sosial, siswa diikutkan kerja bakti, dan kunjungan ke Panti Asuhan. Untuk memaksimalkan pemberdayaan potensi 
siswa dilengkapi dengan buku penghubung informasi sebagai sarana guru dan orang tua dalam memantau aktifitas siswa baik di sekolah maupun dirumah; (3) menjalin kerja sama dengan berbagai pihak untuk mendukung prestasi siswa dilakukan kerjasama dengan orang tua siswa dalam pengadaan media (alat pembelajaran), kegiatan ekstra kurikuler, memberi informasi akses yang terkait dengan kegiatan sekolah yaitu: kerjasama dengan masyarakat dalam menjamin keamanan dan kenyamanan sekolah, serta mendukung kegiatan sekolah, kerjasama dengan pemerintah melalui BOS, Beasiswa Miskin, kerjasama dengan dinas terkait seperti Balai POM, Dinas Kesehatan (Puskemas), dan kerjasama juga dilakukan dengan pihak Bank dan Pegadaian sebagai sponsor.

Faktor- faktor pendukung dalam meningkatkan prestasi siswa di MIT Al-Ishlah Kota Gorontalo yang meliputi: (1) Input siswa yang unggul dan terseleksi, diprioritaskan bagi lulusan RA Al-Ishlah, dan untuk umum dilakukan melalui iklan dengan sistem rangking yang didasarkan pada hasil testing yang terdiri tes psikologi (kemandirian), tes akademik (berhitung dan membaca), tes keterampilan (hafalan surah pendek); (2) Dukungan dari guru-guru di sekolah yaitu nampak pada komitmen guru dalam melaksanakan tugas yang telah ditetapkan, mengikuti rapat setiap hari untuk pemantapan pembelajaran yang dilaksanakan. Guru juga aktif mengikuti pelatihan pembelajaran (excellent service) setiap tahun ajaran baru melalui Jaringan Sekolah Islam Terpadu demi meningkatkan kemampuan profesionalnya.

\section{Saran}

Berdasarkan hasil penelitian ini, maka dikemukakan disarankan kepada pihak-pihak: (1) Kepala Sekolah MIT Al-Ishlah Kota Gorontalo, agar terus meningkatkan strategi dan kerjasama dengan berbagai pihak dalam meningkatkan prestasi peserta didik, dan (2) Guru-guru MIT Al-Ishlah Kota Gorontalo, agar mendukung kepemimpinan kepala sekolah secara bersama untuk pencapaian prestasi sekolah, dan komitmen untuk terus meningkatkan kemampuan profesionalnya.

\section{DAFTAR RUJUKAN}

Bogdan, R.C. \& Biklen, S.K.1982. Qualitative Research for Education: An Introduction to Theory and Methods. Boston: Allyn and Bacon, Inc.

Fauzuddin. 2011. Kepemimpinan Transformasional Kepala Sekolah. Disertasi. Program Pascasarjana universitas Negeri Malang. Tidak dipublikasikan.

Harris, C \& Bennet. 1985. Organizational Theory and Design: Strategic Approach for Management. New York: McGraw-Hill Book Company.

Kartono, K. 2002. Pemimpin dan Kepemimpinan: Apakah pemimpin abnormal itu?. Jakarta: CV. Rajawali.

Owens, R. G. 1991. Organizational Behavior in Education. Englewood Cliffs, New Jersey: Prentice-Hall International Inc.

Rimmer, C \& Davis, B. 1986. Women Principle in Education Departemen, High School in Victoria. The Journal of Education Administration. XXIII (2), 153-187.

Robbins, S. P. 2006. Perilaku Organisasi (Edisi Bahasa Indonesia). PT. Indeks: Gramedia

Sergiovanni, TJ. 1987. The Principleship, A Reflective Practice Perspective. London: Allyn and Bacon, Inc

Slavin, R. E. 2009. Psikologi Pendidikan: Teori dan Praktik (Edisi Kesembilan, Jilid 1). Terjemahan Marianto Samosir. 2011. Jakarta: Indeks.

Suking, A. 2013. Manajemen Peserta Didik Pada Sekolah Efektif. Disertasi. Program Pascasarjana Universitas Negeri Malang. Tidak dipublikasikan.

Tan, M. G (ed). 1991. Perempuan Indonesia Pemimpin Masa Depan?. Jakarta: Pustaka Sinar Harapan.

Triwiyanto, T. 2013. Pemetaan Mutu Manajemen Berbasis Sekolah Melalui Audit Manajemen Pendidikan. Jurnal Manajemen Pendidikan. 24 (2): 125-135.

Ulfatin, N. 2013. Metode Penelitian Kualitatif Di Bidang Pendidikan: Teori dan Aplikasinya. Malang: Bayumedia Publishing. 